\title{
Feeding distillers dried grains in replacement of forage in limit-fed dairy heifer rations: Effects on metabolic profile and onset of puberty
}

\author{
A. K. Manthey, ${ }^{* 1}$ J. L. Anderson, ${ }^{* 2}$ G. A. Perry, $†$ and D. H. Keisler \\ *Dairy Science Department, and \\ †Department of Animal Science, South Dakota State University, Brookings 57007 \\ ‡Division of Animal Sciences, University of Missouri, Columbia 65211
}

\section{ABSTRACT}

The objective of this study was to determine the effect of increasing the inclusion rate of distillers dried grains (DDGS) in replacement of forage in limit-fed diets on the metabolic profile and onset of puberty in dairy heifers. A 16-wk randomized complete block design study was conducted using 48 Holstein heifers (199 \pm 2 d of age) with 3 treatments. Treatments were (1) $30 \%$ DDGS (30DG), (2) $40 \%$ DDGS (40DG), and (3) $50 \%$ DDGS (50DG), with the remainder of the diet consisting of grass hay and $1.5 \%$ mineral mix. Heifers were housed in groups of 6 and individually limit-fed using Calan gates at 2.65, 2.50, and $2.35 \%$ of body weight (BW) on a dry matter (DM) basis for 30DG, 40DG, and 50DG, respectively. Jugular blood samples were collected during wk $0,4,8,12$, and 16 for metabolite and metabolic hormone analysis. Additional samples were taken during wk 16 for plasma fatty acid analysis. When heifers weighed $200 \mathrm{~kg}$, coccygeal vein blood samples were taken twice per week for progesterone analysis to estimate onset of puberty. Blood samples continued until cycling was confirmed via ultrasound for the presence of a corpus luteum. A quadratic response and a linear tendency in the proportion of total fatty acids as linoleic acid were observed. Linear and quadratic responses for plasma concentrations of linoleic acid and arachidonic acid occurred. Overall results for fatty acid analysis demonstrated that total fatty acid and polyunsaturated fatty acids concentration in the blood were linearly increased, with a quadratic response for polyunsaturated fatty acids with 30DG and 50DG having the greatest concentrations. No interactions of treatment by week were observed for any of the metabolites and metabolic hormones measured. Glucose, insulin, insulin-like growth factor-1, leptin, and triglycerides were similar across treatments. A lin-

\footnotetext{
Received September 3, 2016.

Accepted December 14, 2016.

${ }^{1}$ Current address: Hubbard Feeds Inc., Mankato, MN 56001.

${ }^{2}$ Corresponding author: jill.anderson@sdstate.edu
}

ear response of plasma urea nitrogen and a quadratic response tendency for cholesterol concentration were observed. Age and BW at puberty were similar across treatments. Limit-feeding heifers with greater inclusion rates of DDGS maintained energy status without the accumulation of excess adipose tissue as indicated by leptin. Treatments had no detrimental effects on age or BW at puberty.

Key words: distillers grains, metabolic profile, dairy heifer

\section{INTRODUCTION}

Feeding dried distillers grains with solubles (DDGS) has been reported to maintain growth performance and improve feed efficiency in cattle compared with feeding corn and soybean meal (Anderson et al., 2006; Klopfenstein et al., 2008; Schroer et al., 2014). Traditional DDGS has been limited to high-forage diets because of the high fat content (10-15\% ether extract). However, in recent years the fat content of DDGS has been reduced to less than 10\%. Most ethanol manufacturers are removing some of the fat through centrifugation. The reduced fat content in DDGS could allow it to be incorporated into the diets of cattle at much greater proportions. Increasing the inclusion rate of DDGS in the diet would alter the nutrient profile of the diet, which may cause differences in plasma metabolites and metabolic hormone concentrations. This effect is of interest because changes in the metabolic profile, as evaluated by concentrations of circulating blood metabolites and hormones that are linked to energy metabolism, may cause changes in the onset of puberty in cattle (Funston et al., 2012; Perry, 2012) as well as mammary gland development and future milk production (Van Amburgh et al., 1998; Zanton and Heinrichs, 2005).

Age and size are the 2 frequently measured factors that play a role in puberty attainment. Dairy heifers usually reach puberty between 9 and 11 mo of age at an average BW of 250 to $280 \mathrm{~kg}$ (Sejrsen and Purup, 1997). In beef heifers, an increase in ADG can influ- 
ence the age and weight at which heifers attain puberty, with heifers having an increased ADG being heavier at puberty (Short and Bellows, 1971). This increase in ADG may cause an increase in adipose deposition and an increase in leptin concentrations (Zieba et al., 2005). Low ADG have been linked to decreased reproductive performances with decreased percentage bred, reduced pregnancies among animals bred, and greater pregnancy loss (Short and Bellows, 1971).

Leptin has also become of interest with regard to the onset of puberty. When animals have increased adipose deposition, leptin concentration can increase. Leptin and its effect on reproductive status have been investigated in beef heifers. A linear increase in serum leptin concentration from $16 \mathrm{wk}$ before puberty until ovulation in beef heifers was reported (Maciel et al., 2004). Very limited research has been done on leptin concentrations in growing dairy heifers. Anderson et al. (2015) conducted a study with dairy heifers fed a corn- and soybean-based diet, a high-protein DDGS diet with less fat, and a traditional DDGS that was higher in fat and found no differences in plasma leptin concentrations. Chelikani et al. (2009) also conducted a study with dairy heifers fed diets differing in energy and protein level and found no differences among treatments in plasma leptin concentrations at puberty.

The main objective of this study was to determine the effect of increasing the inclusion rate of DDGS in replacement of forage in limit-fed diets on the metabolic profile, as represented by several blood metabolites and hormones that are linked to energy metabolism and onset of puberty in dairy heifers. Because metabolic profile changes can affect reproductive development, a secondary objective was to determine if changes in the metabolic profile would reflect changes in the onset of puberty. The main hypothesis was that changes would occur in the metabolic profile, in particular an increase in plasma concentration of fatty acids and cholesterol, as a result of the increased intake of fat from DDGS. However, heifers would still maintain energy status and blood concentrations of metabolites and hormones related to energy metabolism because of use of a limitfeeding strategy. Another hypothesis was that changes in the onset of puberty would occur as a result of changes in the metabolic profile.

\section{MATERIALS AND METHODS}

\section{Experimental Design}

Samples for this experiment were taken during the previously described feeding study from Manthey et al. (2016); this companion article contains details on the diets, feeding protocols, animal care, and heifer growth performance. All animal use was approved by South Dakota State University Institutional Animal Care and Use Committee. Forty-eight Holstein heifers (199 \pm 2 d of age) housed in pens of 6 were used in a randomized complete block design with 3 treatment diets. The feeding period lasted for $16 \mathrm{wk}$, beginning during the prepubertal period. Treatment diets (Table 1) were (1) high forage with $30 \%$ of diet as corn DDGS (30DG), (2) moderate forage with $40 \%$ of diet as corn DDGS (40DG), and (3) low forage with $50 \%$ of diet as corn DDGS (50DG) on DM basis. The forage portion of the diets consisted of grass hay. The amount of feed offered was determined as a percentage of BW and decreased with increasing concentrations of DDGS to allow for similar intakes of energy across treatments. Diets were fed at $2.65,2.50$, and $2.35 \%$ of $\mathrm{BW}$ for 30DG, 40DG, and 50DG, respectively (DM basis). Diets were formulated using the NRC (2001) to provide similar energy intakes when fed to a 250-kg BW Holstein heifer. Heifers were fed individually using a Calan gate feeding system (American Calan Inc., Northwood, NH). Nutrient composition and average intakes are also provided in Table 1.

\section{Sample Collection and Analysis}

For the analysis of cholesterol, glucose, insulin, IGF1, leptin, plasma urea nitrogen, and triglycerides, blood samples were taken on 2 consecutive days during wk $0,4,8,12$, and 16 of the feeding study. Blood samples were taken approximately $4 \mathrm{~h}$ after feeding $(1230 \mathrm{~h})$ via venipuncture of the jugular vein into vacutainer tube (Becton, Dickinson, and Company, Franklin Lakes, NJ) containing sodium fluoride and potassium oxalate for glucose analysis (cat. no. 367925) or $\mathrm{K}_{2} \mathrm{EDTA}$ for all other analyses (cat. no. 366643). Following blood collection, samples were immediately placed on ice and brought into the laboratory for processing within $3 \mathrm{~h}$ of collection. Blood collection tubes were centrifuged at $1,000 \times g$ for $20 \mathrm{~min}$ at $4^{\circ} \mathrm{C}$ (Centrifuge CR412, Jouan Inc., Winchester, VA). Plasma ( $\mathrm{K}_{2}$ EDTA tubes) or serum (sodium fluoride and potassium oxalate tubes) was then transferred to polystyrene tubes, using a plastic transfer pipette, and frozen at $-20^{\circ} \mathrm{C}$ until further processing and analysis. When samples were analyzed for metabolites or hormones, both plasma or serum samples from the 2 consecutive days during each of the blood sampling weeks (wk 0, 4, 8, 12, and 16) were analyzed and then averaged by week for statistical analysis.

Metabolites (cholesterol, glucose, plasma urea nitrogen, and triglycerides) were analyzed with commer- 
cially available enzymatic or colorimetric assay kits on a microplate spectrophotometer (Cary 50, Varian Inc., Walnut Creek, CA). Total plasma cholesterol was analyzed using cholesterol esterase and oxidase (cat. no. C7510; Pointe Scientific Inc., Canton, MI) as described by Allain et al. (1974). Serum glucose was analyzed using glucose oxidase as described by Trinder (1969) (cat. no. G7521; Pointe Scientific Inc.). Plasma urea nitrogen was analyzed using diacetylmonoxime (Procedure 0508; Stanbio Laboratory, Boerne, TX). Plasma triglyceride concentration was analyzed using glycerol phosphate oxidase after hydrolysis by lipoprotein lipase as described by Fossati and Prencipe (1982) that paired the reaction with the classic Trinder (1969) reaction.

Samples were sent to the University of Missouri for IGF-1 and leptin analysis. Plasma concentrations of IGF-1 and leptin were determined via double-antibody RIA previously validated by the University of Missouri laboratory and inter- and intraassay coefficients of variation $(\mathbf{C V})$ were $<5 \%$ (Lalman et al., 2000; Delavaud et al., 2000).

Insulin was analyzed using a commercially available insulin assay (MP Biomedical, Solon, OH) according to the manufacturer's directions. Increasing volumes of bovine serum $(25,50,75$, and $100 \mathrm{~mL})$ produced a displacement curve that was parallel $(P=0.60)$ to the standard curve (slope $=1.93 \pm 0.22$ for standard curve; slope $=1.77 \pm 0.20$ for bovine serum). Addition of known amounts of insulin (35 and $155 \mathrm{mIU} / \mathrm{mL}$ ) to cow serum were accurately recovered $(106 \%)$. Interand intraassay CV were 10.10 and $3.85 \%$, respectively, and assay sensitivity was $5.5 \mathrm{mIU} / \mathrm{mL}$.

During wk 16, an extra 8-mL blood sample was collected from each heifer, and plasma was collected as previously described for plasma fatty acid determination. Plasma lipid extractions were performed as described by Bligh and Dyer (1959). Extracted lipids were then prepared for fatty acid analysis using butylation methods as described by Sukhija and Palmquist (1988) with adaptations by Abdelqader et al. (2009). Feed samples for fatty acid analysis were collected, and 4- or 5-mo composites of DDGS and grass hay were analyzed for fatty acid profiles via direct butylation techniques (Abdelqader et al., 2009). All prepared fatty acid samples were analyzed via GC (Hewlett Packard 6890, Palo Alto, CA) as described by Abdelqader et al. (2009).

To determine onset of puberty, additional blood samples were taken for progesterone analysis. Sampling began when heifers reached $200 \mathrm{~kg}$ of BW and continued until presence of a corpus luteum was confirmed via ultrasonography (Agroscan AL, Echo Control Medical, Angoulême, France). After heifers reached 9 mo of age, ultrasonography began and was performed once weekly independent of blood sampling until a corpus luteum was identified, at which time ultrasonography and blood sampling ceased. Blood samples were taken via coccygeal venipuncture into vacutainer tubes containing $\mathrm{K}_{2}$ EDTA twice weekly (Tuesday and Friday) approximately $4 \mathrm{~h}$ post feeding. Plasma was harvested as previously described. Plasma progesterone concentrations were determined using a validated RIA procedure as described by Engel et al. (2008). Inter- and intraassay CV were 13.3 and $2.46 \%$, respectively, and assay sensitivity was $0.4 \mathrm{ng} / \mathrm{mL}$. Precycling baseline progesterone concentrations were $0.55,0.52$, and 0.67 $\mathrm{ng} / \mathrm{mL}$ for $30 \mathrm{DG}, 40 \mathrm{DG}$, and 50DG, respectively (SEM $=0.089, P=0.13)$. Heifers were determined to have reached puberty when progesterone concentrations were greater than $1 \mathrm{ng} / \mathrm{mL}$, indicating that ovulation had occurred and a corpus luteum had formed.

Table 1. Ingredients, nutrient composition, and nutrient intakes of diets with increasing inclusion amounts of distillers dried grains with solubles (DDGS) in replacement of grass hay limit-fed to growing replacement Holstein dairy heifers

\begin{tabular}{|c|c|c|c|}
\hline \multirow[b]{2}{*}{ Item $^{2}$} & \multicolumn{3}{|c|}{ Treatment $^{1}$} \\
\hline & $30 \mathrm{DG}$ & $40 \mathrm{DG}$ & $50 \mathrm{DG}$ \\
\hline \multicolumn{4}{|l|}{ Ingredient, $\%$ of DM } \\
\hline DDGS & 30.0 & 40.0 & 50.0 \\
\hline Grass hay & 68.5 & 58.5 & 48.5 \\
\hline Vitamin and mineral premix ${ }^{3}$ & 0.75 & 0.75 & 0.75 \\
\hline Limestone & 0.30 & 0.30 & 0.30 \\
\hline Sodium bicarbonate & 0.30 & 0.30 & 0.30 \\
\hline Salt & 0.15 & 0.15 & 0.15 \\
\hline \multicolumn{4}{|l|}{ Nutrient ${ }^{4}$} \\
\hline $\mathrm{DM}, \%$ & 86.7 & 86.7 & 86.8 \\
\hline $\mathrm{CP}$ & 16.8 & 19.2 & 21.5 \\
\hline $\mathrm{NDF}$ & 54.4 & 50.8 & 47.1 \\
\hline Ether extract (petroleum) & 3.06 & 3.74 & 4.41 \\
\hline Starch & 2.38 & 2.89 & 3.41 \\
\hline ME, Mcal/kg of DM & 2.27 & 2.39 & 2.51 \\
\hline $\mathrm{NE}_{\mathrm{G}}, \mathrm{Mcal} / \mathrm{kg}$ of DM & 0.81 & 0.90 & 0.99 \\
\hline \multicolumn{4}{|l|}{ Nutrient intake, kg/d } \\
\hline $\mathrm{DM}$ & 6.49 & 6.21 & 5.84 \\
\hline $\mathrm{CP}$ & 1.09 & 1.19 & 1.26 \\
\hline NDF & 3.53 & 3.15 & 2.75 \\
\hline Ether extract (petroleum) & 0.20 & 0.23 & 0.26 \\
\hline $\mathrm{ME}, \mathrm{Mcal} / \mathrm{kg}$ of DM & 14.7 & 14.8 & 14.7 \\
\hline $\mathrm{NE}_{\mathrm{G}}, \mathrm{Mcal} / \mathrm{kg}$ of DM & 5.25 & 5.59 & 5.78 \\
\hline
\end{tabular}

${ }^{1} 30 \mathrm{DG}=30 \%$ dietary inclusion rate of DDGS; $40 \mathrm{DG}=40 \%$ dietary inclusion rate of DDGS; 50DG $=50 \%$ dietary inclusion rate of DDGS. ${ }^{2}$ Formulated using NRC (2001).

${ }^{3}$ Contained $2.2 \mathrm{~g} / \mathrm{kg}$ of lasalocid, $14.5 \% \mathrm{Ca}, 8.0 \% \mathrm{P}, 21.0 \% \mathrm{NaCl}, 2.5 \%$ $\mathrm{Mg}, 1.5 \% \mathrm{~K}, 2.0 \% \mathrm{~S}, 4,100 \mathrm{mg} / \mathrm{kg} \mathrm{Mn}, 1,250 \mathrm{mg} / \mathrm{kg} \mathrm{Cu}, 70 \mathrm{mg} / \mathrm{kg}$ Co, $70 \mathrm{mg} / \mathrm{kg} \mathrm{I}, 53 \mathrm{mg} / \mathrm{kg} \mathrm{Se}, 5,500 \mathrm{mg} / \mathrm{kg} \mathrm{Zn}, 325 \mathrm{mg} / \mathrm{kg}$ Fe, 704,000 $\mathrm{IU} / \mathrm{kg}$ vitamin $\mathrm{A}, 140,800 \mathrm{IU} / \mathrm{kg}$ vitamin $\mathrm{D}_{3}$, and $5,280 \mathrm{IU} / \mathrm{kg}$ vitamin E (Future Cow Supreme Premix B2000, Land O'Lakes Inc., St. Paul, $\mathrm{MN})$.

${ }^{4} \%$ of DM, unless otherwise noted. 


\section{Statistical Analysis}

All data were analyzed using SAS version 9.4 (SAS Institute Inc., Cary, NC). Feed fatty acid analysis data were compiled for the 4- or 5-mo feed composite analysis, and standard errors were calculated using the MEANS procedure in SAS. Dietary fatty acid values were calculated based on analysis of the grass hay and DDGS for each treatment over the course of the study. Fatty acid intake and plasma and serum metabolites and metabolic hormones were analyzed as a randomized complete block design with repeated measured using the MIXED procedures of SAS 9.4 with week as the repeated measure using heifer (block) as the subject (Littell et al., 2006). The model included treatment, week, and treatment $\times$ week interactions. Initial metabolites and metabolic hormones were included as covariates within the model. Akaike's criterion was used to determine the most suitable covariance structure in repeated measures for each parameter. Covariance structures tested were compound symmetry, first-order autoregressive, Toeplitz, and unstructured. Compound symmetry yielded the least absolute Akaike's values and was used for the final model. The MIXED procedures of SAS 9.4 were used for the analysis of plasma fatty acid profile. The model included only treatment with block included as a random variable because it was based on samples taken during only wk 16 of the study. Puberty data were analyzed as binomial data (cycling or not cycling) by age or weight. Puberty data were also analyzed using repeated measures by $10-\mathrm{d}$ and $10-\mathrm{kg}$ intervals of age and BW. Significant differences among treatments for all analyses were declared at $P \leq 0.05$, and tendencies were declared at $0.05<P$ $\leq 0.10$. Linear and quadratic effects of treatments were analyzed using orthogonal contrasts.

\section{RESULTS AND DISCUSSION}

\section{Dietary Fatty Acids}

The fatty acid profiles of the grass hay and DDGS used in the experimental diets are shown in Table 2. Grass hay had greater proportions of medium- and longchain fatty acids (C10:0, C12:0, C12:1, C16:1, C20:0, and C18:3n-3), while DDGS had greater concentrations of total and long-chain fatty acids (C14:0, C16:0, C18:1 cis-11, and C18:2 cis-9,cis-12). Fatty acids profiles of these feedstuffs were consistent with those found by Leonardi et al. (2005) and Anderson et al. (2015), who found that dietary long-chain fatty acid concentration increased with increasing inclusion rate of DDGS. Fatty acid profiles of the experimental diets are found in Table
3. More total and long-chain fatty acids (C16:0, C18:1 cis-11, and C18:2 cis-9,cis-12) were present as dietary concentrations of DDGS increased. Differences in fatty acid profiles of the diets were further reflected in the fatty acid intake (Table 4). Intakes of medium-chain fatty acids (C10:0, C12:0, C12:1) linearly decreased $(P<0.01)$ with increasing concentrations of DDGS. However, intake of medium- and long-chain fatty acids (C14:0, C16:0, C18:1 cis-11, and $\mathrm{C} 18: 2$ cis-9, cis-12) increased $(P<0.01)$ with increasing concentrations of

Table 2. Fatty acid composition of the grass hay and distillers dried grains with solubles (DDGS) used in the treatment diets limit-fed to growing Holstein dairy heifers

\begin{tabular}{|c|c|c|c|c|}
\hline \multirow[b]{2}{*}{ Fatty acid $^{1}$} & \multicolumn{2}{|c|}{ Grass hay } & \multicolumn{2}{|c|}{ DDGS } \\
\hline & Mean & $\mathrm{SE}$ & Mean & $\mathrm{SE}$ \\
\hline \multicolumn{5}{|l|}{$\mathrm{g} / 100 \mathrm{~g}$ of fatty acid } \\
\hline C10:0 & 5.23 & 0.835 & 0.81 & 0.052 \\
\hline $\mathrm{C} 12: 0$ & 3.60 & 0.396 & 0.52 & 0.015 \\
\hline $\mathrm{C} 12: 1$ & 10.4 & 0.745 & 0.70 & 0.012 \\
\hline C14:0 & 1.27 & 0.066 & 5.05 & 0.033 \\
\hline C16:0 & 7.36 & 0.301 & 12.5 & 0.060 \\
\hline C16:1 & 5.81 & 0.346 & 0.14 & 0.003 \\
\hline C18:0 & 0.78 & 0.066 & 1.79 & 0.008 \\
\hline $\mathrm{C} 18: 1$ cis-11 & 1.35 & 0.135 & 17.3 & 0.047 \\
\hline $\mathrm{C} 18: 1$ trans -11 & 0.10 & 0.036 & 0.74 & 0.003 \\
\hline $\mathrm{C} 18: 2$ cis- 9, cis-12 & 4.30 & 0.297 & 49.0 & 0.234 \\
\hline C18:3n-6 & 0.40 & 0.033 & 0.55 & 0.240 \\
\hline C18:3n-3 & 22.8 & 0.804 & 3.50 & 0.036 \\
\hline $\mathrm{C} 18: 2 \operatorname{trans}^{2}$ & 1.46 & 0.086 & 0.17 & 0.004 \\
\hline C20:0 & 18.2 & 1.033 & 4.76 & 0.042 \\
\hline $\mathrm{C} 20: 4$ & 0.43 & 0.128 & 0.13 & 0.002 \\
\hline Others $^{3}$ & 16.5 & 0.388 & 2.33 & 0.021 \\
\hline \multicolumn{5}{|l|}{$\mathrm{g} / \mathrm{kg}$ of $\mathrm{DM}$} \\
\hline C10:0 & 1.05 & 0.176 & 0.66 & 0.069 \\
\hline C12:0 & 0.72 & 0.076 & 0.42 & 0.006 \\
\hline $\mathrm{C} 12: 1$ & 2.07 & 0.144 & 0.56 & 0.031 \\
\hline $\mathrm{C} 14: 0$ & 0.25 & 0.015 & 4.06 & 0.151 \\
\hline C16:0 & 1.46 & 0.029 & 10.1 & 0.391 \\
\hline C16:1 & 1.16 & 0.088 & 0.11 & 0.005 \\
\hline C18:0 & 0.16 & 0.009 & 1.44 & 0.065 \\
\hline $\mathrm{C} 18: 1$ cis-11 & 0.27 & 0.018 & 13.9 & 0.633 \\
\hline C18:1 trans-11 & 0.02 & 0.007 & 0.59 & 0.025 \\
\hline $\mathrm{C} 18: 2$ cis- 9, cis-12 & 0.86 & 0.056 & 39.3 & 1.528 \\
\hline C18:3n-6 & 0.08 & 0.004 & 0.46 & 0.203 \\
\hline C18:3n-3 & 4.56 & 0.313 & 2.81 & 0.113 \\
\hline $\mathrm{C} 18: 2$ trans $^{2}$ & 0.29 & 0.008 & 0.13 & 0.009 \\
\hline $\mathrm{C} 20: 0$ & 3.63 & 0.246 & 3.83 & 0.189 \\
\hline $\mathrm{C} 20: 4$ & 0.09 & 0.027 & 0.11 & 0.005 \\
\hline Others $^{3}$ & 3.29 & 0.033 & 1.87 & 0.079 \\
\hline Total & 19.9 & 0.665 & 80.4 & 3.487 \\
\hline
\end{tabular}

${ }^{1}$ Represented as number of carbons:number of double bonds.

${ }^{2}$ Includes all C18:2 trans isomers.

${ }^{3}$ Sum of C4:0, C5:0, C6:0, C7:0, C8:0, C9:0, C11:0, C11:1, C13:0, C13:1, C14:1, C15:0, C15:1, C16:1 trans, C17:0, C17:1, C18:1 trans-6, C18:1 trans-9, C18:1 trans-10, C18:1 cis-9, C20:1,5, C20:1,8, C20:1 cis, C18:2 trans-10,cis-12, C18:2 cis-9,trans-11, C20:2,11,14, C20:3 homo $\gamma$, C22:0, C20:3,11,14,17, C22:1, C23:0, C20:5, C22:2, C24:0, C22:3, C22:4, C24:1, C22:5n-3, C22:6, and unidentified fatty acids. 
Table 3. Fatty acid compositions of the treatment diets with increasing inclusion amounts of distillers dried grains with solubles (DDGS) in replacement of grass hay limit-fed to growing Holstein dairy heifers

\begin{tabular}{|c|c|c|c|c|c|c|}
\hline \multirow{3}{*}{$\begin{array}{l}\text { Fatty acid, }{ }^{1} \mathrm{~g} / \mathrm{kg} \\
\text { of DM }\end{array}$} & \multicolumn{6}{|c|}{ Treatment $^{2}$} \\
\hline & \multicolumn{2}{|c|}{$30 \mathrm{DG}$} & \multicolumn{2}{|c|}{$40 \mathrm{DG}$} & \multicolumn{2}{|c|}{$50 \mathrm{DG}$} \\
\hline & Mean & SE & Mean & SE & Mean & $\mathrm{SE}$ \\
\hline $\mathrm{C} 10: 0$ & 0.92 & 0.141 & 0.88 & 0.130 & 0.84 & 0.119 \\
\hline C12:0 & 0.62 & 0.051 & 0.59 & 0.043 & 0.56 & 0.035 \\
\hline $\mathrm{C} 12: 1$ & 1.59 & 0.107 & 1.43 & 0.096 & 1.28 & 0.085 \\
\hline C14:0 & 1.39 & 0.043 & 1.77 & 0.058 & 2.15 & 0.074 \\
\hline C16:0 & 4.02 & 0.103 & 4.88 & 0.144 & 5.74 & 0.185 \\
\hline C16:1 & 0.83 & 0.061 & 0.72 & 0.053 & 0.62 & 0.044 \\
\hline C18:0 & 0.54 & 0.014 & 0.67 & 0.021 & 0.80 & 0.029 \\
\hline C18:1 cis-11 & 4.37 & 0.180 & 5.73 & 0.244 & 7.10 & 0.309 \\
\hline $\mathrm{C} 18: 1$ trans- 11 & 0.19 & 0.011 & 0.25 & 0.013 & 0.31 & 0.015 \\
\hline C18:2 cis-9,cis-12 & 12.4 & 0.44 & 16.2 & 0.59 & 20.1 & 0.75 \\
\hline C18:3n-6 & 0.19 & 0.060 & 0.23 & 0.081 & 0.27 & 0.101 \\
\hline C18:3n-3 & 3.96 & 0.234 & 3.79 & 0.210 & 3.61 & 0.187 \\
\hline $\mathrm{C} 18: 2$ trans $^{3}$ & 0.24 & 0.003 & 0.22 & 0.002 & 0.21 & 0.001 \\
\hline $\mathrm{C} 20: 0$ & 3.64 & 0.157 & 3.66 & 0.137 & 3.68 & 0.123 \\
\hline $\mathrm{C} 20: 4$ & 0.09 & 0.020 & 0.09 & 0.018 & 0.10 & 0.016 \\
\hline Others ${ }^{4}$ & 2.82 & 0.045 & 2.68 & 0.050 & 2.53 & 0.055 \\
\hline Total & 37.8 & 1.403 & 43.8 & 1.690 & 49.9 & 1.982 \\
\hline
\end{tabular}

${ }^{1}$ Represented as number of carbons:number of double bonds.

${ }^{2} 30 \mathrm{DG}=30 \%$ dietary inclusion rate of DDGS; 40DG $=40 \%$ dietary inclusion rate of DDGS; $50 \mathrm{DG}=50 \%$ dietary inclusion rate of DDGS.

${ }^{3}$ Includes all C18:2 trans isomers.

${ }^{4}$ Sum of C4:0, C5:0, C6:0, C7:0, C8:0, C9:0, C11:0, C11:1, C13:0, C14:1, C15:0, C15:1, C16:1 trans, C17:0, C17:1, C18:1 trans-6, C18:1 trans-9, C18:1 trans-10, C18:1 cis-9, C20:1,5, C20:1,8, C20:1 cis, C18:2 trans10,cis-12, C18:2 cis-9,trans-11, C20:2,11,14, C20:3 homo $\gamma$, C22:0, C20:3,11,14,17, C22:1, C23:0, C20:5, C22:2, C24:0, C22:3, C22:4, C24:1, C22:5n-3, C22:6, and unidentified fatty acids.

Table 4. Mean fatty acid intakes for Holstein heifers fed increasing inclusion amounts of distillers dried grains with solubles (DDGS) in replacement of grass hay in limit-fed rations

\begin{tabular}{|c|c|c|c|c|c|c|c|c|c|}
\hline Fatty acid, g/d & \multicolumn{3}{|c|}{ Treatment $^{1}$} & SEM & \multicolumn{5}{|c|}{$P$-value ${ }^{2}$} \\
\hline C10:0 & 5.94 & 5.44 & 4.90 & 0.148 & $<0.01$ & $<0.01$ & 0.17 & $<0.01$ & 0.89 \\
\hline $\mathrm{C} 12: 1$ & 10.28 & 8.90 & 7.50 & 0.241 & $<0.01$ & $<0.01$ & $<0.01$ & $<0.01$ & 0.97 \\
\hline C14:0 & 9.02 & 10.99 & 12.56 & 0.307 & $<0.01$ & $<0.01$ & $<0.01$ & $<0.01$ & 0.60 \\
\hline C16:0 & 26.09 & 30.29 & 33.54 & 0.842 & $<0.01$ & $<0.01$ & $<0.01$ & $<0.01$ & 0.64 \\
\hline C18:1 cis-11 & 28.32 & 35.59 & 41.49 & 1.000 & $<0.01$ & $<0.01$ & $<0.01$ & $<0.01$ & 0.58 \\
\hline C18:1 trans -11 & 1.24 & 1.54 & 1.79 & 0.043 & $<0.01$ & $<0.01$ & $<0.01$ & $<0.01$ & 0.59 \\
\hline C18:2 cis-9,cis-12 & 80.36 & 100.77 & 117.33 & 2.832 & $<0.01$ & $<0.01$ & $<0.01$ & $<0.01$ & 0.58 \\
\hline C18:3n-6 & 1.25 & 1.43 & 1.57 & 0.040 & $<0.01$ & $<0.01$ & $<0.01$ & $<0.01$ & 0.66 \\
\hline C18:3n-3 & 25.71 & 23.51 & 21.11 & 0.638 & $<0.01$ & $<0.01$ & 0.13 & $<0.01$ & 0.90 \\
\hline $\mathrm{C} 18: 2$ trans $^{3}$ & 1.55 & 1.38 & 1.21 & 0.038 & $<0.01$ & $<0.01$ & $<0.01$ & $<0.01$ & 0.93 \\
\hline C20:0 & 23.58 & 22.69 & 21.47 & 0.617 & 0.06 & $<0.01$ & 0.98 & 0.02 & 0.83 \\
\hline
\end{tabular}

${ }^{1} 30 \mathrm{DG}=30 \%$ dietary inclusion rate of DDGS; 40DG $=40 \%$ dietary inclusion rate of DDGS; 50DG $=50 \%$ dietary inclusion rate of DDGS. ${ }^{2}$ Significance of effects for treatment (Trt), week (wk), treatment $\times$ week (Trt $\times$ wk), and linear (L) and quadratic (Q) orthogonal contrasts. ${ }^{3}$ Includes all C18:2 trans isomers.

${ }^{4}$ Sum of C4:0, C5:0, C6:0, C7:0, C8:0, C9:0, C11:0, C11:1, C13:0, C13:1, C14:1, C15:0, C15:1, C16:1 trans, C17:0, C17:1, C18:1 trans-6, C18:1 trans-9, C18:1 trans-10, C18:1 cis-9, C20:1,5, C20:1,8, C20:1 cis, C18:2 trans-10,cis-12, C18:2 cis-9,trans-11, C20:2,11,14, C20:3 homo $\gamma$, C22:0, C20:3,11,14,17, C22:1, C23:0, C20:5, C22:2, C24:0, C22:3, C22:4, C24:1, C22:5n-3, C22:6, and unidentified fatty acids. 
DDGS, which is of interest because linoleic acid (C18:2) is a precursor for arachidonic acid (C20:4), which is used in the synthesis of prostaglandins (Funston, 2004).

\section{Metabolites and Metabolic Hormones}

Average plasma fatty acid proportions ( $\mathrm{mg} / 100 \mathrm{mg}$ of fatty acids) and concentrations ( $\mu \mathrm{g} / \mathrm{mL}$ of plasma) are presented in Tables 5 and 6 , respectively. A quadratic effect $(P=0.04)$ and a linear tendency $(P=0.07)$ were observed for an increase in the proportion of total fatty acids as linoleic acid (C18:2) with increasing dietary inclusion of DDGS. Linoleic acid also accounted for the greatest proportion of fatty acids across all treatments. Plasma concentration of linoleic acid also linearly increased $(P<0.01)$ with increasing dietary concentrations of DDGS. All heifers also had a large proportion of plasma fatty acid as oleic acid (C18:1 cis-9), but plasma concentrations were not affected by treatment $(P=0.95)$. Plasma concentration of palmitic acid (C16:0) linearly increased $(P=0.02)$ with increasing dietary concentrations of DDGS as expected by experimental diets. A quadratic effect $(P=0.04)$ was apparent for arachidonic acid (C20:4), which is the precursor for the synthesis of prostaglandins, with the 30DG and 50DG treatments having a greater concentration than the 40DG treatment (Funston, 2004). Overall results for fatty acid analysis demonstrated that plasma total fatty acid concentration linearly increased $(P=0.02)$ and PUFA concentration increased with a quadratic effect $(P=0.03)$, meaning that the 30DG and 50DG treatments had a greater concentration than the 40DG as dietary concentration of DDGS increased. More specifically, a marked increase occurred in plasma total fatty acids and PUFA in the heifers fed 50DG, and less of a difference was found between heifers fed the 30DG or 40DG diets. These results are consistent with Anderson et al. (2015), who also found that plasma linoleic acid proportion was increased in diets with increased dietary fat concentrations from DDGS. Plasma linoleic acid concentration also increased in diets with increased dietary fat from DDGS (Anderson et al., 2015). Additionally, an increase was observed in palmitic acid in diets containing DDGS in the experiment conducted by Anderson et al. (2015). However, the metabolic effects of these fatty acid changes in dairy heifers are not yet fully understood.

Blood metabolite and metabolic hormone concentrations are presented in Table 7 . No treatment by week interactions were found for any of the metabolites or metabolic hormones measured. Despite differences in total plasma fatty acid concentrations, no differences occurred in concentrations of plasma triglycerides, which are composed of fatty acid chains and a glycerol backbone and serve as a major storage form of fat in the body. This finding differs from the results reported by Park et al. (1983) in which heifers were fed diets with increasing levels of dietary fat. Increasing the inclusion of sunflower seeds (20 to $30 \%$ of dietary DM) resulted in elevated triglyceride concentrations in the blood (Park et al., 1983). However, despite the lack of differences in triglycerides, a quadratic tendency $(P=0.10)$ was observed for plasma cholesterol. Other researchers have reported increases in plasma cholesterol with increased dietary fat concentrations (Park et al., 1983; Talavera et al., 1985; Thomas et al., 1997; Funston, 2004). The increased plasma cholesterol concentration in the 30DG treatment is speculated to be a result of increased rumen acetate concentration and proportion (Manthey et al., 2016). Plasma cholesterol concentration drastically increased $(P<0.01)$ during the first 4 wk of the trial and then continued to gradually increase over the remainder of the feeding period, with the exception of 40DG, which decreased during wk 16 (Figure 1). Cholesterol is an important metabolite in reproduction because it is a precursor for steroid hormone synthesis. Progesterone may be more easily affected by plasma cholesterol concentration than other steroid hormones such as estradiol (Talavera et al., 1985). In cattle, the rate-limiting step in progesterone synthesis is the conversion of cholesterol to pregnenolone, and cholesterol as well as pregnenolone are needed for estradiol synthesis (Talavera et al., 1985). However, because of the scope of this study, progesterone was not sampled at the frequency necessary to monitor concentrations throughout the estrous cycle.

Concentrations of serum glucose did not differ across treatments. Previous research has reported decreases in blood glucose concentration in dairy heifers fed diets with elevated fat concentrations (9.2 and $13.1 \%$; Park et al., 1980). This finding was attributed to the decreased availability of gluconeogenic nutrients in diets with elevated fat concentrations as well as changes in rumen fermentation resulting in a greater acetate:propionate ratio with decreased propionate production, a gluconeogenic precursor (Park et al., 1980). The lack of differences in the current study may be attributed to the dietary treatments providing enough energy and CP. A treatment effect existed for plasma urea nitrogen $(P$ $<0.01$ ) with increasing concentrations of DDGS. Over the course of the study, plasma urea nitrogen increased $(P<0.01)$. This increase can be explained by the increase in dietary CP across treatments (Table 1). Other research has reported an inverse relationship between dietary CP and plasma cholesterol concentration (Park et al., 1980). However, diets in the current study were 
Table 5. Plasma fatty acid profile from wk 16 of the feeding period for Holstein heifers fed increasing amounts of distillers dried grains with solubles (DDGS) in replacement of grass hay in limit-fed rations

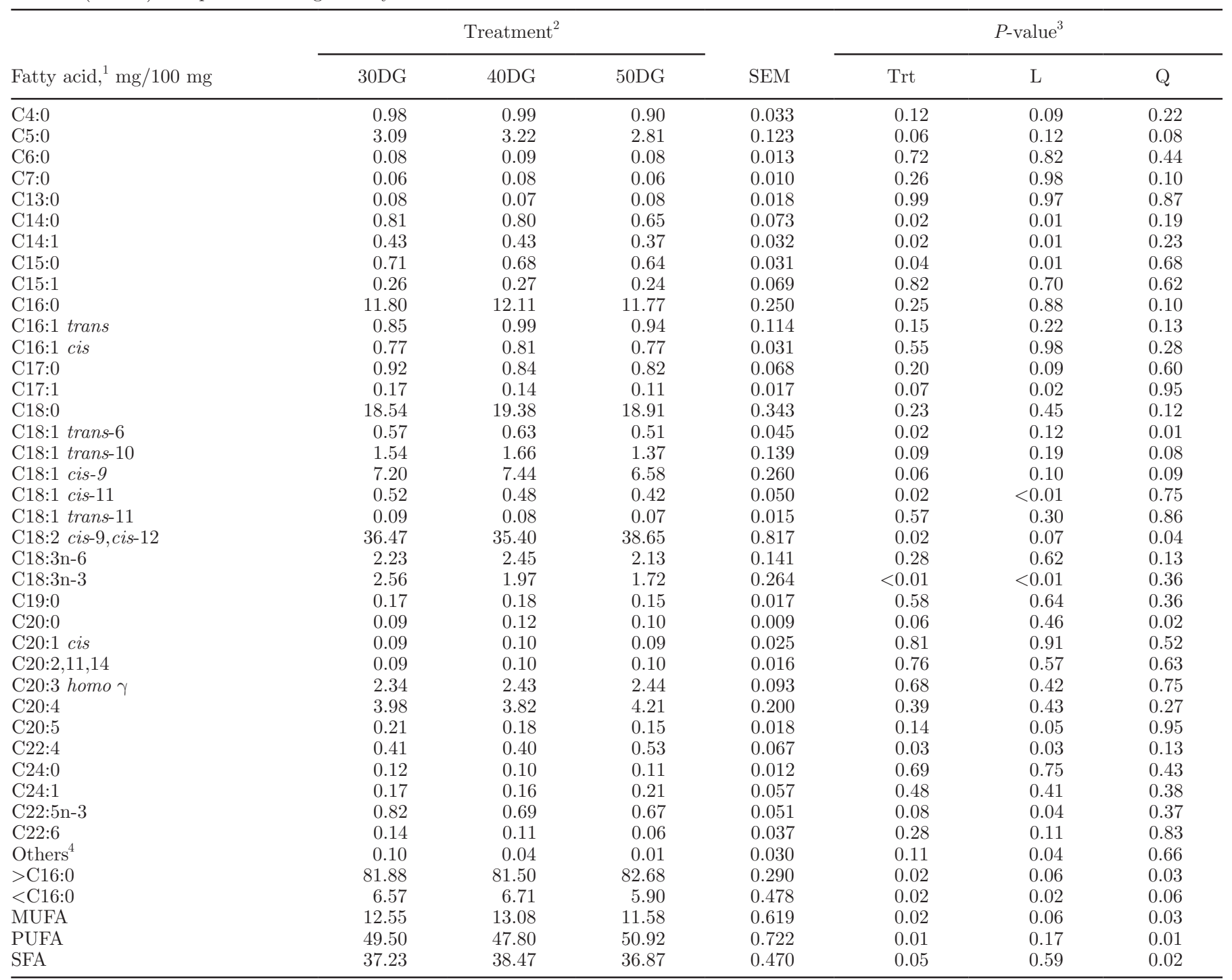

${ }^{1}$ Represented as number of carbons:number of double bonds.

${ }^{2} 30 \mathrm{DG}=30 \%$ dietary inclusion rate of DDGS; 40DG $=40 \%$ dietary inclusion rate of DDGS; $50 \mathrm{DG}=50 \%$ dietary inclusion rate of DDGS.

${ }^{3}$ Significance of effects for treatment (Trt) and linear (L) and quadratic (Q) orthogonal contrasts.

${ }^{4}$ Sum of C8:0, C9:0, C10:0, C11:0, C12:0, C12:1, C18:1 trans-9, C20:1,5, C20:1,8, C18:2 trans-9,trans-10,11,12, C18:2 cis-9,trans-11, C18:2 trans10, cis-12, C18:2 cis-10,12, C22:0, C22:3,11,14,17, C22:1, C22:2, C22:3, and unidentified fatty acids.

not deficient in $\mathrm{CP}$ as reflected by plasma urea nitrogen, and dietary CP differences cannot explain differences in plasma cholesterol concentration.

No differences occurred in plasma insulin, IGF-1, or leptin concentrations. However, the concentrations of plasma IGF-1 decreased from wk 0 to 4 , then increased across treatments over the remainder of the study ( $P$ $<0.01$; Figure 2). Other nutrients such as starch and protein can also influence energy balance and are further discussed in Manthey et al. (2016). Prior to the start of the study, heifers were being fed a diet with greater starch concentration than any of the treatment diets, which may account for the decrease in plasma concentrations of IGF-1 from wk 0 to 4 . Plant oils with greater concentrations of PUFA have led to increases in serum concentrations of cholesterol and insulin to enhance IGF-1 production by luteal tissue in vitro (Talavera et al., 1985; Wehrman et al., 1991; Ryan et al., 1995). The significant concentrations of PUFA in DDGS may explain the greater average numerical con- 
centration of plasma IGF-1 concentration in the 50DG diet; however, results were not significant. Also, IGF-1 is capable of activating insulin receptors at greater concentrations, but no differences were reflected in plasma insulin concentrations. A major component of the fatty acid profile of DDGS is linoleic acid, resulting in the production of propionate in the rumen that can be used in gluconeogenesis (Palmquist, 1981; Chalupa et al., 1986). In the rumen, lipids containing linoleic acid are converted to glycerol and free fatty acids. Glycerol can then be converted to propionate and be used for gluconeogenesis (Chalupa et al., 1984). However, increased gluconeogenesis did not produce differences in plasma concentrations of insulin in the current study. The results from the current study agree with those reported by Anderson et al. (2015), in which DDGS was limit-fed at up to $30 \%$ of dietary DM and no differences in plasma insulin were observed, suggesting that shortterm energy status was maintained by feeding DDGS compared with corn and soybean meal.

Table 6. Plasma fatty acid concentrations from wk 16 of the feeding period for Holstein heifers fed increasing amounts of distillers dried grains with solubles (DDGS) in replacement of grass hay in limit-fed rations

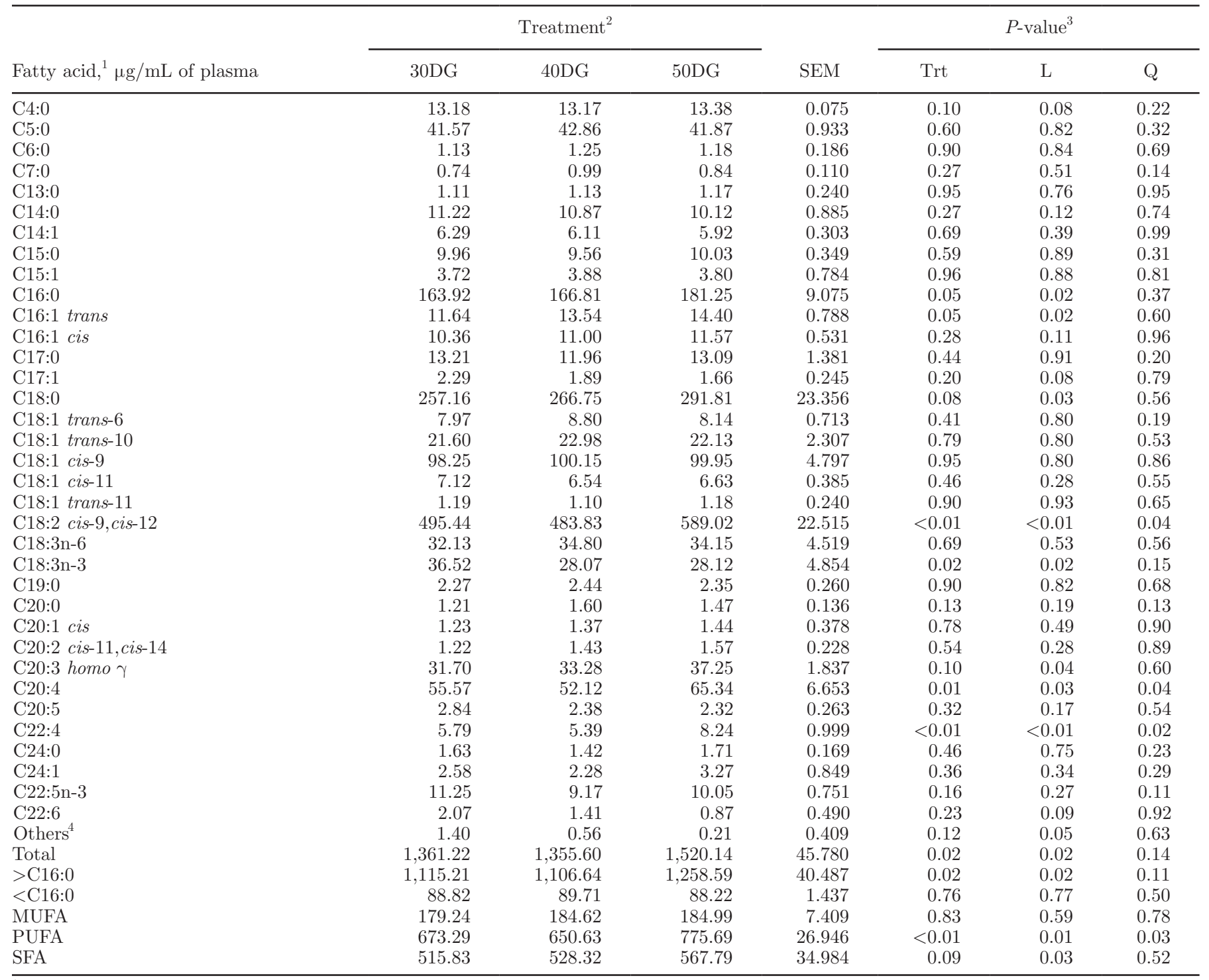

${ }^{1}$ Represented as number of carbons:number of double bonds.

${ }^{2} 30 \mathrm{DG}=30 \%$ dietary inclusion rate of DDGS; $40 \mathrm{DG}=40 \%$ dietary inclusion rate of DDGS; $50 \mathrm{DG}=50 \%$ dietary inclusion rate of DDGS.

${ }^{3}$ Significance of effects for treatment (Trt) and linear (L) and quadratic (Q) orthogonal contrasts.

${ }^{4}$ Sum of C8:0, C9:0, C10:0, C11:0, C12:0, C12:1, C18:1 trans-9, C20:1,5, C20:1,8, C18:2 trans-9,trans-10,11,12, C18:2 cis-9,trans-11, C18:2 trans10, cis-12, C18:2 cis-10,12, C22:0, C22:3,11,14,17, C22:1, C22:2, C22:3, and unidentified fatty acids. 
Table 7. Plasma metabolites and metabolic hormone concentrations for Holstein heifers fed increasing amounts of distillers dried grains with solubles (DDGS) in replacement of grass hay in limit-fed rations

\begin{tabular}{|c|c|c|c|c|c|c|c|c|c|}
\hline \multirow[b]{2}{*}{ Item } & \multicolumn{3}{|c|}{ Treatment $^{1}$} & \multirow[b]{2}{*}{ SEM } & \multicolumn{5}{|c|}{$P$-value ${ }^{2}$} \\
\hline & $30 \mathrm{DG}$ & $40 \mathrm{DG}$ & $50 \mathrm{DG}$ & & Trt & wk & Trt $\times$ wk & $\mathrm{L}$ & $\mathrm{Q}$ \\
\hline Glucose, ${ }^{3} \mathrm{mg} / \mathrm{dL}$ & 76.26 & 77.74 & 77.33 & 1.67 & 0.81 & 0.10 & 0.88 & 0.65 & 0.65 \\
\hline IGF-1, ng/mL & 102.7 & 100.0 & 109.4 & 4.27 & 0.29 & $<0.01$ & 0.30 & 0.27 & 0.25 \\
\hline Insulin, ng/mL & 1.05 & 1.12 & 1.15 & 0.099 & 0.78 & $<0.01$ & 0.61 & 0.50 & 0.84 \\
\hline Leptin, ng/mL & 4.42 & 4.35 & 4.59 & 0.091 & 0.19 & 0.14 & 0.57 & 0.22 & 0.18 \\
\hline
\end{tabular}

${ }^{1} 30 \mathrm{DG}=30 \%$ dietary inclusion rate of DDGS; 40DG $=40 \%$ dietary inclusion rate of DDGS; $50 \mathrm{DG}=50 \%$ dietary inclusion rate of DDGS

${ }^{2}$ Significance of effects for treatment (Trt), week (wk), treatment $\times$ week (Trt $\times$ wk), and linear (L) and quadratic (Q) orthogonal contrasts.

${ }^{3}$ Glucose was measured from serum samples instead of plasma.

Long-term energy status was maintained as demonstrated by plasma concentrations of leptin (Zieba et al., 2005). Importantly, plasma concentrations of leptin remained fairly constant throughout the study (Figure 3), indicating no treatment was gaining adiposity compared with the others. This finding is in agreement with previous research on differing dietary fat concentrations in beef (Garcia et al., 2003) and dairy heifers (Block et al., 2003; Chelikani et al., 2009; Anderson et al., 2015). The maintenance of short- and long-term energy status was supported by the maintenance of growth (Manthey et al., 2016), suggesting that heifers use the fat and protein from DDGS as energy in replacement of forage fiber and protein when utilizing a limit-feeding strategy.

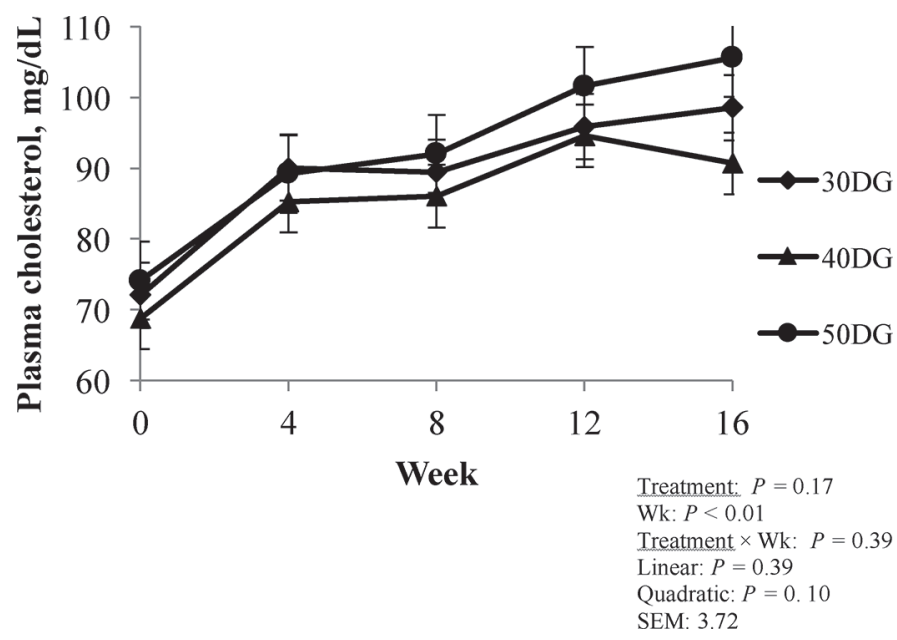

Figure 1. Concentrations of plasma cholesterol in Holstein heifers limit-fed treatment diets with increasing amounts of distillers dried grains with solubles (DDGS) in replacement of grass hay. 30DG, $40 \mathrm{DG}$, and $50 \mathrm{DG}=30,40$, and $50 \%$ dietary inclusion rate of DDGS, respectively. Error bars represent the SEM.

\section{Puberty}

Mean age and BW at puberty are presented in Table 8. Despite no differences, values follow a similar numerical pattern as plasma cholesterol, a precursor to reproductive hormones, with 40DG having the lowest plasma cholesterol concentrations as well as numerically the highest age and BW at puberty. Holstein heifers attain puberty between 9 and 11 mo of age at a BW of 250 to $280 \mathrm{~kg}$ (Sejrsen and Purup, 1997). However, others have reported $\mathrm{BW}$ close to $300 \mathrm{~kg}$ at the onset of puberty (Zanton and Heinrichs, 2007; Chelikani et al., 2003, 2009). Heifers in the current study averaged $253.9 \mathrm{~kg}$ of $\mathrm{BW}$ at the onset of puberty, suggesting that these heifers may have entered precocious puberty. The percentages of heifers cycling over time by age and BW are presented in Figures 4 and 5, respectively. A

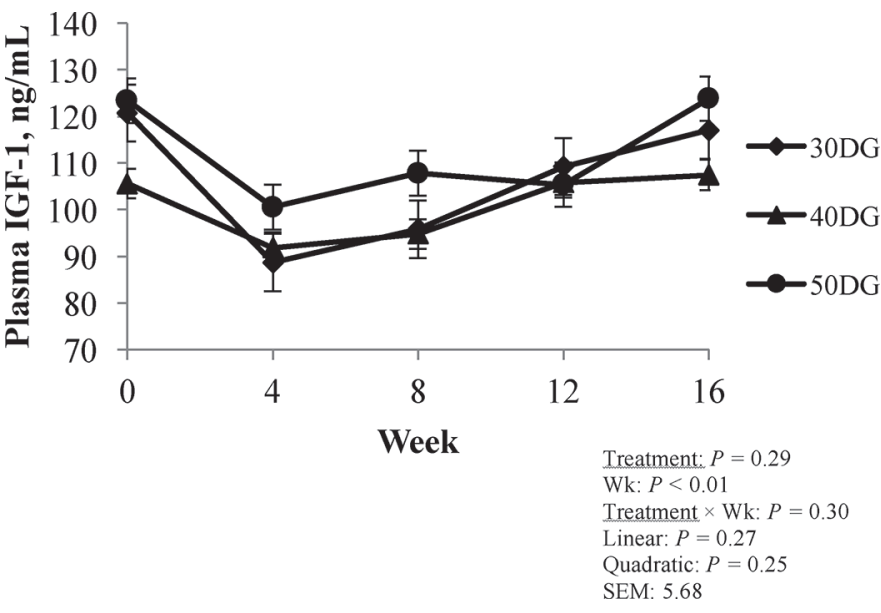

Figure 2. Plasma concentrations of IGF-1 in Holstein heifers limitfed treatment diets with increasing amounts of distillers dried grains with solubles (DDGS) in replacement of grass hay. 30DG, 40DG, and $50 \mathrm{DG}=30,40$, and $50 \%$ dietary inclusion rate of DDGS, respectively. Error bars represent the SEM. 
Table 8. Mean age and BW at puberty for Holstein heifers fed increasing amounts of distillers dried grains with solubles (DDGS) in replacement of grass hay in limit-fed rations

\begin{tabular}{lcccrcc}
\hline & \multicolumn{3}{c}{ Treatment $^{1}$} & & \multicolumn{2}{c}{$P$-value } \\
\cline { 2 - 4 } Item & \multirow{2}{*}{$30 \mathrm{DG}$} & $40 \mathrm{DG}$ & $50 \mathrm{DG}$ & \multirow{2}{*}{ SEM } & Trt $^{2}$ \\
\hline Age at puberty, d & 234.6 & 244.3 & 235.5 & 13.7 & 0.80 \\
BW at puberty, kg & 246.4 & 261.3 & 254.0 & 24.9 & 0.59 \\
\hline
\end{tabular}

${ }^{1} 30 \mathrm{DG}=30 \%$ dietary inclusion rate of DDGS; $40 \mathrm{DG}=40 \%$ dietary inclusion rate of DDGS; $50 \mathrm{DG}=50 \%$

dietary inclusion rate of DDGS.

${ }^{2} \mathrm{Trt}=$ treatment.

treatment by age interaction $(P<0.01)$ occurred for the onset of puberty, with a larger proportion of heifers fed 50DG cycling at a younger age than 30DG and 40DG heifers. Attainment of puberty is also thought to be correlated with body fat content (Zieba et al., 2004; Perry, 2012). However, Chelikani et al. (2003) found that when heifers were fed diets differing in energy and protein density, no differences in BW or body composition occurred. In the current study no differences were found in plasma concentrations of leptin, which are partially indicative of body fat deposition. However, circulating plasma cholesterol and fatty acids differed and may have played a larger role in the onset of puberty. Anderson et al. (2015) also found similar results in plasma cholesterol and fatty acids on the onset of puberty, but more research is necessary to confirm this speculation.

\section{CONCLUSIONS}

As originally hypothesized, increasing the dietary inclusion amounts of DDGS changed the metabolic profile of dairy heifers. Total plasma fatty acids and

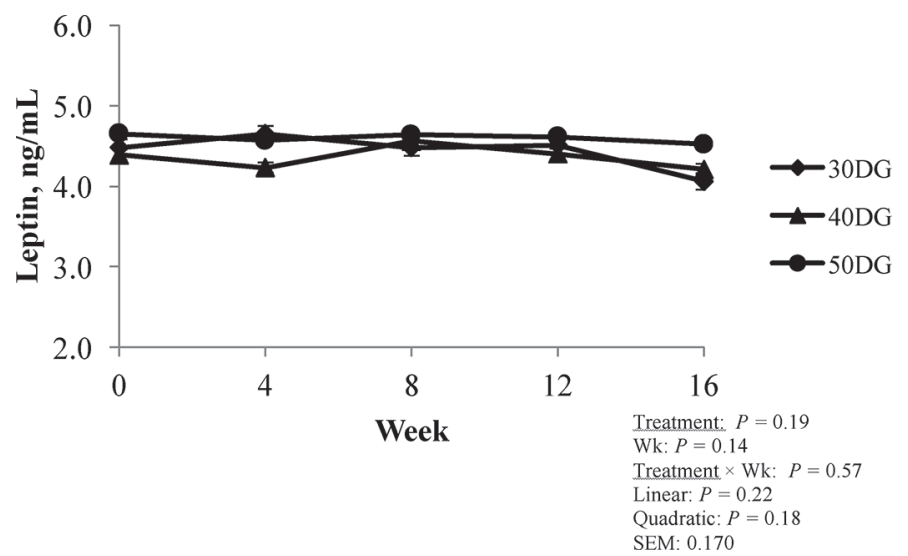

Figure 3. Plasma concentrations of leptin in Holstein heifers limitfed treatment diets with increasing amounts of distillers dried grains with solubles (DDGS) in replacement of grass hay. 30DG, 40DG, and $50 \mathrm{DG}=30,40$, and $50 \%$ dietary inclusion rate of DDGS, respectively. Error bars represent the SEM.
PUFA were altered by dietary treatments, and plasma concentrations of cholesterol tended to be altered. However, heifers maintained energy status without accumulating excess adipose tissue, as indicated by plasma leptin concentrations. Plasma concentrations of linoleic acid and arachidonic acid, which are precursors for prostaglandins, increased as a result of increasing the dietary inclusion rate of DDGS. A treatment by age interaction occurred for the onset of puberty, with a larger percentage of 50DG heifers beginning to cycle at a younger age; however, no differences were observed in average age or BW at puberty. Overall, this research indicates that DDGS could be incorporated into growing dairy heifer limit-fed rations at up to $50 \%$ of dietary DM without causing negative effects on short- or longterm energy status or onset of puberty.

\section{ACKNOWLEDGMENTS}

Funding for this research was provided by the Minnesota Corn Research and Promotion Council (Shakopee, MN) and the Minnesota Agricultural Utilization Research Institute (Crookston, MN) with support

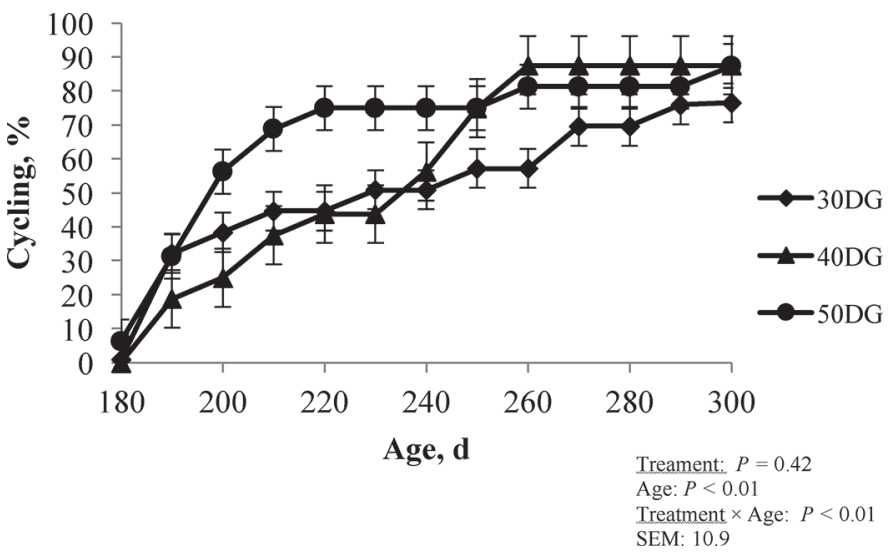

Figure 4. Percentage of Holstein heifers pubertal (cycling) by age that were limit-fed increasing amounts of distillers dried grains with solubles (DDGS) in replacement of grass hay. 30DG, 40DG, and 50DG $=30,40$, and $50 \%$ dietary inclusion rate of DDGS, respectively. Error bars represent the SEM. 


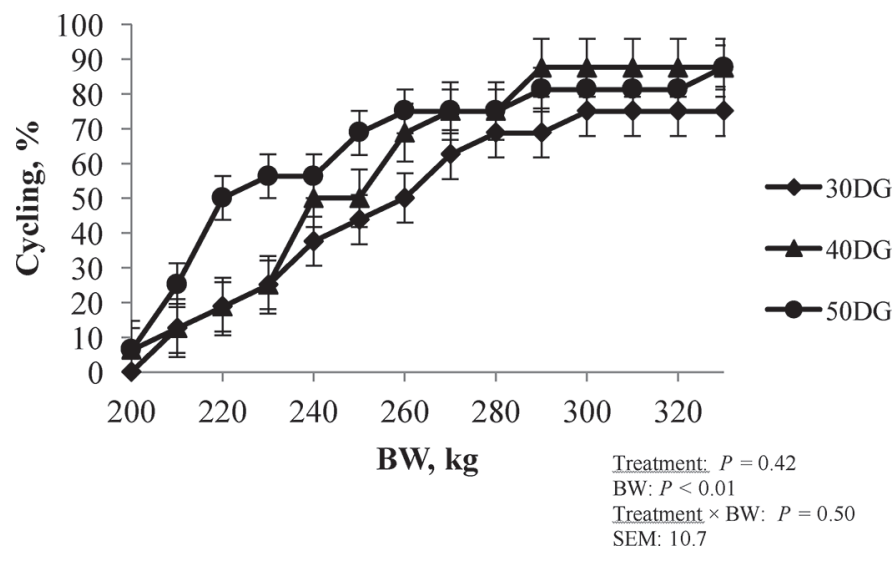

Figure 5. Percentage of Holstein heifers pubertal (cycling) by BW that were limit-fed increasing amounts of distillers dried grains with solubles (DDGS) in replacement of grass hay. 30DG, 40DG, and 50DG $=30,40$, and $50 \%$ dietary inclusion rate of DDGS, respectively. Error bars represent the SEM.

provided from the South Dakota Agricultural Experiment Station (Brookings, SD). It also contributes to the USDA North Central Cooperative Research Project NC-2042: Management Systems to Improve Economic and Environmental Sustainability of Dairy Enterprises. The authors thank fellow graduate students and farm personnel in the Dairy Science Department at South Dakota State University (Brookings) at the time this study was conducted for their help with sampling and animal care.

\section{REFERENCES}

Abdelqader, M. M., A. R. Hippen, K. F. Kalscheur, D. J. Schingoethe, K. Karges, and M. L. Gibson. 2009. Evaluation of corn germ from ethanol production as an alternative fat source in dairy cow diets. J. Dairy Sci. 92:1023-1037.

Allain, C. C., L. S. Poon, C. S. G. Chan, W. Richmond, and P. C. Fu. 1974. Enzymatic determination of total serum cholesterol. Clin. Chem. 20:470-475.

Anderson, J. L., K. F. Kalscheur, J. A. Clapper, G. A. Perry, D. H. Keisler, A. D. Garcia, and D. J. Schingoethe. 2015. Feeding fat from distillers dried grains with solubles to dairy heifers: II. Effects on metabolic profile. J. Dairy Sci. 98:5709-5719.

Anderson, J. L., D. J. Schingoethe, K. F. Kalscheur, and A. R. Hippen. 2006. Evaluation of dried and wet distillers grains included at two concentrations in the diets of lactating dairy cows. J. Dairy Sci. 89:3133-3142.

Bligh, E. G., and W. J. Dyer. 1959. A rapid method for total extraction and purification. Can. J. Biochem. Physiol. 37:911-917.

Block, S. S., J. M. Smith, R. A. Ehrhardt, M. C. Diaz, R. P. Rhoads, M. E. Van Amburgh, and Y. R. Boisclair. 2003. Nutritional and developmental regulation of plasma leptin in dairy cattle. J. Dairy Sci. 86:3206-3214.

Chalupa, W., B. Rickabaugh, D. S. Kronfeld, and D. Sklan. 1984. Rumen fermentation in vitro as influenced by long chain fatty acids. J. Dairy Sci. 67:1439-1444.

Chalupa, W., B. Vecchiarelli, A. Elser, D. S. Kronfeld, D. Sklan, and D. L. Palmquist. 1986. Ruminal fermentation in vivo as influenced by long-chain fatty acids. J. Dairy Sci. 69:1293-1301.
Chelikani, P. K., D. J. Ambrose, D. H. Keisler, and J. J. Kennelly. 2009. Effects of dietary energy and protein density on plasma concentrations of leptin and metabolic hormones in dairy heifers. J. Dairy Sci. 92:1430-1441.

Chelikani, P. K., J. D. Ambrose, and J. J. Kennelly. 2003. Effect of dietary energy and protein density on body composition, attainment of puberty, and ovarian follicular dynamics in dairy heifers. Theriogenology 60:707-725.

Delavaud, C., F. Bocquier, Y. Chilliard, D. H. Keisler, A. Gertler, and G. Kann. 2000. Plasma leptin determination in ruminants: Effect of nutrition status and body fatness on plasma leptin concentration assessed by a specific RIA in sheep. J. Endocrinol. 165:519-526.

Engel, C. L., H. H. Patterson, and G. A. Perry. 2008. Effect of dried corn distillers grains plus solubles compared with soybean hulls, in late gestation heifer diets, on animal and reproductive performance. J. Anim. Sci. 86:1697-1708.

Fossati, P., and L. Prencipe. 1982. Serum triglycerides determined colorimetrically with an enzyme that produces hydrogen peroxide. Clin. Chem. 28:2077-2080.

Funston, R. N. 2004. Fat supplementation and reproduction in beef females. J. Anim. Sci. 82(E-Suppl):E154-E161.

Funston, R. N., J. L. Martin, D. M. Larson, and A. J. Roberts. 2012. Physiology and endocrinology symposium: Nutritional aspects of developing replacement heifers. J. Anim. Sci. 90:1166-1171.

Garcia, M. R., M. Amstanden, C. D. Morrison, D. H. Keisler, and G. L. Williams. 2003. Age at puberty, total fat and conjugated linoleic acid content of carcass, and circulating metabolic hormones in beef heifers fed a diet high in linoleic acid beginning at four months of age. J. Anim. Sci. 81:261-268.

Klopfenstein, T. J., G. E. Erickson, and V. R. Bremer. 2008. Board invited review: Use of distillers by-products in the beef cattle feeding industry. J. Anim. Sci. 86:1223-1231.

Lalman, D. L., J. E. Williams, B. W. Hess, M. G. Thomas, and D. H. Keisler. 2000. Effect of dietary energy on milk production and metabolic hormones in thin primiparous beef heifers. J. Anim. Sci. $78: 530-538$

Leonardi, C., S. Bertics, and L. E. Armentano. 2005. Effect of increasing oil from distillers grains or corn oil on lactation performance. J. Dairy Sci. 88:2820-2827.

Littell, R. C., G. A. Milliken, W. W. Stroup, R. D. Wolfinger, and O. Schabenberger. 2006. SAS for Mixed Models. 2nd ed. SAS Institute, Cary, NC.

Maciel, M. N., D. A. Zieba, M. Amstalden, D. H. Keisler, J. P. Neves, and G. L. Williams. 2004. Chronic administration of recombinant ovine leptin in growing beef heifers: Effects on secretion of LH, metabolic hormones, and timing of puberty. J. Anim. Sci. 82:29302936.

Manthey, A. K., J. L. Anderson, and G. A. Perry. 2016. Feeding distillers dried grains in replacement of forage in limit-fed dairy heifer rations: Effects on growth performance, rumen fermentation, and total-tract digestibility of nutrients. J. Dairy Sci. 99:7206-7215.

NRC. 2001. Nutrient Requirements of Dairy Cattle. 7th rev. ed. Natl. Acad. Press, Washington, DC.

Palmquist, D. L. 1981. Metabolite, insulin, and growth hormone concentrations in blood plasma of cows fed high fat diets for entire lactations. J. Dairy Sci. 64(Suppl. 1):159. (Abstr.)

Park, C. S., G. R. Fisher, and C. N. Haugse. 1980. Effect of dietary protein and sunflower meal on blood serum cholesterol of dairy heifers. J. Dairy Sci. 63:1451-1461.

Park, C. S., W. Rafalowski, and G. D. Marx. 1983. Effect of dietary fat supplement on lipid metabolism on Holstein heifers. J. Dairy Sci. 66:528-534.

Perry, G. A. 2012. Harnessing basic knowledge of factors controlling puberty to improve synchronization of estrus and fertility in heifers. J. Anim. Sci. 90:1172-1182.

Ryan, D. P., B. Bao, M. K. Griffith, and G. L. Williams. 1995. Metabolic and luteal sequelae to heightened dietary fat intake in undernourished, anestrous beef cows induced to ovulate. J. Anim. Sci. 73:2086-2093.

Schroer, R. C., T. D. Nennich, T. S. Dennis, M. M. Schutz, S. S. Donkin, and D. Little. 2014. Intake and growth of prepubertal 
dairy heifers fed reduced-fat dried distillers grains. Prof. Anim. Sci. 30:93-98.

Sejrsen, K., and S. Purup. 1997. Influence of prepubertal feeding level on milk yield potential of dairy heifers: A review. J. Anim. Sci. 75:828-835.

Short, R. E., and R. A. Bellows. 1971. Relationships among weight gains, age at puberty, and reproductive performance in heifers. J. Anim. Sci. 32:127-131.

Sukhija, P. S., and D. L. Palmquist. 1988. A rapid method for determination of total fatty acid content and composition of feedstuffs and feces. J. Agric. Food Chem. 36:1202-1206.

Talavera, F., C. S. Park, and G. L. Williams. 1985. Relationships among dietary lipid intake, serum cholesterol, and ovarian function in Holstein heifers. J. Anim. Sci. 60:1045-1051.

Thomas, M. G., B. Bao, and G. L. Williams. 1997. Dietary fats varying in their fatty acid composition differentially influence follicular growth in cows fed isoenergetic diets. J. Anim. Sci. 75:2512-2519.

Trinder, P. 1969. Determination of glucose in blood using glucose oxidase with an alternative oxygen receptor. Ann. Clin. Biochem. $6: 24-27$.

Van Amburgh, M. E., D. M. Galton, D. E. Bauman, R. W. Everett, D. G. Fox, L. E. Chase, and H. N. Erb. 1998. Effects of three prepu- bertal body growth rates on performance of Holstein heifers during first lactation. J. Dairy Sci. 81:527-538.

Wehrman, M. E., T. H. Welsh Jr., and G. L. Williams. 1991. Dietinduced hyperlipidemia in cattle modifies the intrafollicular cholesterol environment, modulates ovarian follicular dynamics, and hastens the onset of postpartum luteal activity. Biol. Reprod. 45:514-522.

Zanton, G. I., and A. J. Heinrichs. 2005. Meta-analysis to assess effect of prepubertal average daily gain of Holstein heifers on firstlactation production. J. Dairy Sci. 88:3860-3867.

Zanton, G. I., and A. J. Heinrichs. 2007. The effects of controlled feeding of a high-forage or high-concentrate ration on heifer growth and first-lactation milk production. J. Dairy Sci. 90:3388-3396.

Zieba, D. A., M. Amstalden, S. Morton, M. N. Maciel, D. H. Keisler, and G. L. Williams. 2004. Regulatory roles of leptin at the hypothalamic-hypophyseal axis before and after sexual maturation in cattle. Biol. Reprod. 71:804-812.

Zieba, D. A., M. Amstalden, and G. L. Williams. 2005. Regulatory roles of leptin in reproduction and metabolism: A comparative review. Domest. Anim. Endocrinol. 29:166-185. 